\title{
THE HYDRAULIC CONDUCTIVITY OF MODEL SOIL- BENTONITE CUT-OFF WALL BACKFILLS UNDER CALCIUM CHLORIDE SOLUTION
}

\author{
WANG, R. ${ }^{1,2,3}-$ XU, H. Q. ${ }^{1,3^{*}}-$ ZHOU, A. Z. ${ }^{3}$ - JiANG, P. M. ${ }^{1,3}-$ LIU, S. Q. ${ }^{3}-$ SONG, M. M. ${ }^{3}$ \\ ${ }^{1}$ Joint Technology Transfer Center of Yancheng Polytechnic College, 224005 Yancheng, P. R. \\ China \\ ${ }^{2}$ Shandong Academy of Building Research, 250000 Jinan, P. R. China \\ ${ }^{3}$ School of Architecture and Civil Engineering, Jiangsu University of Science and Technology, \\ 212003 Zhenjiang, P. R. China \\ *Corresponding author \\ e-mail: hankinxu@163.com; phone: +86-157-5177-8209; fax: +86-0515-8858-3900
}

(Received 28 $8^{\text {th }}$ Mar 2019; accepted 22 $2^{\text {nd }}$ May 2019)

\begin{abstract}
In landfill, cut-off walls have been widely used as in situ barriers to isolate contaminants and control the migration of contaminated groundwater. How the permeability of the wall changes as exposed to pollutants is unclear. In view of this issue, Fujian standard sand was used to simulate the stratum, and four clay were used as the mixed material. After mixing, pouring and consolidation, the hydraulic conductivity and water characteristic curve were measured. The results showed that when the permeation of the sand-clay mixtures was stabilized by a $0.2 \mathrm{~mol} / \mathrm{L}$ calcium chloride solution under the additive amount of $10 \%$ clay, the hydraulic conductivity increased to different degrees compared with that permeated with tap water, but did not increase more than tenfold. Moreover, the porosity didn't change significantly after the stabilization of the permeation of the calcium chloride solution in the four kinds of sand-clay mixtures but decreased slightly. The experimental results showed that the replacement between calcium ions and univalent cations on the surface of clay mineral particles decreases the thickness of the diffused double layer and the content of bound water; thus, the effective porosity increases, which may be the main reason for the increase of the permeability.
\end{abstract}

Keywords: regional soil and water contamination, landfills, engineering barriers, leachate, permeability

\section{Introduction}

With the rapid economic development and the improvement of urbanization in China, the output of garbage is increasing, as is the number of landfills. In 2008, the environmental protection special inspection campaign of eight ministries and commissions of the State Council carried out a diagnostic investigation of the scale of landfill sites, anti-seepage measures, and the operation of leachate treatment facilities throughout the country. The results showed that there are 935 open and closed refuse landfills in China, 34\% of which do not take anti-seepage measures. These simple landfills without strict designs and construction, especially those without a bottom seepage control system, have become a major environmental hazard. In the future, the number of pollution control projects needed for this kind of landfills will increase gradually. It is very difficult and costly to rebuild horizontal seepage control systems in the bottom of exhausted landfills. Therefore, constructing a closed vertical cut-off wall has been widely applied. Soil-bentonite cut-off walls are also used to prevent pollutants from leaking into the groundwater and soil at the Rocky Mountain Arsenal site (Patton et 
al., 2007), which is a chemical weapons and pesticide production wasteland in the United States. It is also common to make up for the loss or failure of horizontal anti-seepage systems by using a vertical cut-off wall. There are few reports of concrete examples of vertical cut-off wall construction in existing refuse landfills in China, but vertical antiseepage control systems have also been used in the construction of new landfills. During the $4^{\text {th }}$ phase construction of the Shanghai Laogang Municipal Solid Waste Landfill built on the intertidal zone, a vertical cut-off wall of cement-bentonite was applied to the new landfill (Fei et al., 2005). In summing up the technology of vertical cut-off walls, Yao and Bao mentioned that the plain-type landfills of the Shanghai Laogang $4^{\text {th }}$ Phase, Central Tangshan, Gangyang, and Taizhou all adopted anti-seepage control methods combining the horizontal and vertical methods (Yao and Bao, 2008). The horizontal-vertical antiseepage system was also used in the expansion of the Landfill in Qizi Mountain, Suzhou.

Concerning the aspects of the material, design and construction of vertical cut-off walls, in summing up the vertical cut-off technology of landfills in our country, Jing et al. thought that because of a late start, the methods of water conservancy, geology and civil engineering of the anti-seepage material and construction technology were borrowed, especially grouting anti-seepage technology (Jing et al., 2006). In addition, theoretical or technical methods for anti-seepage of landfills have not been developed yet. However, cut-off walls of soil-clay material have good engineering characteristics, and the anti-seepage and anti-fouling properties have received much attention. The construction procedure of clay-based vertical cut-off walls is to excavate the trench first and adopt $4 \% \sim 6 \%$ mud counterfort at the same time, mix the excavated stratum and clay proportionally, and then mix the produced mixture fully with the mud in the trench (Rumer and Ryan, 1995). Then, the sand-clay mixture is backfilled with a collapsing slump of $100 \sim 150 \mathrm{~mm}$, and a vertical cut-off barrier with a hydraulic conductivity of less than $10^{-7} \mathrm{~cm} / \mathrm{s}$ is formed. Devlin and Parker have studied the anti-fouling performance of soil-bentonite cut-off walls (Devlin and Parker, 1996). Through theoretical calculations, it was concluded that when the thickness of the cut-off wall is 1 $\mathrm{m}$ and the hydraulic conductivity is less than $5 \times 10^{-8} \mathrm{~cm} / \mathrm{s}$, the hydraulic transportation of pollutants can be effectively controlled, and the escape of pollutants mainly occurs through the slow molecular diffusion process. Thus, how to make the hydraulic conductivity of the clay and stratum less than $5 \times 10^{-8} \mathrm{~cm} / \mathrm{s}$ has become an important problem in engineering.

The chemical compatibility between the backfill material of cut-off wall and the contaminants in the leachate is very important for clay-based cut-off walls. For example, the hydraulic conductivity of the backfill material of soil-bentonite cut-off walls, geosynthetic clay liners (GCL) and compacted sand-bentonite mixtures may increase due to the interaction between the backfill material and inorganic cations (Jo et al., 2005; Katsumi et al., 2008). Grube found that when sodium hydroxide solution permeated soilbentonite backfill material, the impermeability decreased by $5 \sim 10$ times (Grube, 1992). The increase of the concentration of organic solutions and electrolyte solutions or the effect of strong acid solution will change the structure of clay, especially bentonite, and lead to an increase by orders of magnitude in the hydraulic conductivity. Lee et al. found that the liquid limit, settling volume and expansion index create a critical threshold for the increase of the hydraulic conductivity through permeability testing and settlement testing (Lee et al., 2005). Fan et al. mixed lead nitrate solution of different concentrations with kaolin-bentonite to simulate cut-off wall contamination by lead (Fan et al., 2013). They carried out consolidation tests and settlement tests. The hydraulic conductivity of 
the mixture increased $2 \sim 15$ times with the increase of the lead concentration. This was attributed to the compression of the double layer and the change of the surface charge of the soil particles.

The above research reveals that the change of the electrochemical environment in soil has a key effect on the hydraulic conductivity, but it can also be seen that the change rule of the hydraulic conductivity is not uniform in terms of quantity because of the different types of clay used. It is obvious that the chemical substances not only change the viscosity of the permeant fluid but also block the movement of water, and changes of the electrochemical environment in the soil and changes of the bound water around the clay particles result in the change of the micro-pore structure. This may be the main reason why the effects of chemical solutions are different from those of water permeation. Thus, it is necessary to study the influence of chemical solutions on the hydraulic conductivity when using different clay minerals. In this research, four kinds of clay are used to carry out laboratory experiments.

\section{Materials and Methods}

\section{Materials}

Because the stratum varies according to the site conditions, considering the adverse conditions of the soil layer properties in the simulated site, Fujian standard sand (commercial) is selected to simulate the stratum and is hereinafter referred to as FSS,. The basic physical properties are shown in Table 1 (Hu and Yang, 2012).

Table 1. Physical properties of the model stratum

\begin{tabular}{c|c|c|c|c|c}
\hline $\boldsymbol{G}_{\mathbf{s}}$ & $\boldsymbol{C}_{\mathbf{u}}$ & $\rho_{\mathrm{dmax}}\left(\mathbf{g} / \mathbf{c m}^{\mathbf{3}}\right)$ & $\rho_{\mathrm{dmin}}\left(\mathbf{g} / \mathbf{c m}^{\mathbf{3}}\right)$ & $\boldsymbol{e}_{\max }$ & $\boldsymbol{e}_{\min }$ \\
\hline 2.64 & 5.99 & 1.74 & 1.43 & 0.85 & 0.52 \\
\hline
\end{tabular}

Table 2. Geotechnical properties of the four clays

\begin{tabular}{c|c|c|c|c}
\hline Type & $\boldsymbol{G}_{\mathbf{s}}$ & $\boldsymbol{w}_{\mathbf{L}}(\boldsymbol{\%})$ & $\boldsymbol{w}_{\mathbf{p}}(\boldsymbol{\%})$ & Swell index $(\mathbf{m L} /(\mathbf{2 g}))$ \\
\hline Clay-K & 2.68 & 39 & 23 & 2.6 \\
Clay-J & 2.72 & 48 & 24 & 3.1 \\
Clay-A & 2.72 & 53 & 27 & 4.1 \\
Bent-A & 2.70 & 301 & 56 & 38.5 \\
\hline
\end{tabular}

The four kinds of natural clay (powdery) are as follows. Clay- $\mathrm{K}$ is produced in Lingshou County, Shijiazhuang, Hebei Province, and the main clay mineral is kaolinite; Clay-J is produced in Jiangning District, Nanjing, Jiangsu Province, and the main clay mineral is illite; Clay-A is produced in the Inner Mongolia Autonomous Region, and the main clay mineral is palygorskite; and Bent-A is produced in Anji, Huzhou, Zhejiang, and the main clay mineral is montmorillonite. The basic physical properties of the above four kinds of clay are obtained according to the Standard for Soil Test Method (GB/T 
50123-1999) and Bentonite (GB/T 20973-2007), as shown in Table 2. The clay and standard sand are dried at $105^{\circ} \mathrm{C}$ for $24 \mathrm{~h} \sim 48 \mathrm{~h}$.

Permeability tests of permeant fluids are carried out using tap water and $\mathrm{CaCl}_{2}$ solution, respectively. The properties of these fluids are shown in Table 3. The reason why we choose $\mathrm{CaCl}_{2}$ solution is because of the widespread use of $\mathrm{CaCl}_{2}$ to evaluate the effects of multivalent cations on hydraulic conductivity in previous experimental studies (Shackelford et al., 2000). Although various multivalent cations may be contained in the leachate of the actual landfill, the influence of these cations on the chemical compatibility of the clay barriers will not be very different. For example, the experiments of Jo et al. and Kolstad et al. show that the types of the divalent cations $\left(\mathrm{Cu}^{2+}, \mathrm{Mg}^{2+}, \mathrm{Zn}^{2+}\right.$ and $\left.\mathrm{Ca}^{2+}\right)$ have no significant effect on the free expansion and hydraulic conductivity of GCL at a given concentration (Jo et al., 2001; Kolstad et al., 2004).

Table 3. Basic properties of the permeant fluids used

\begin{tabular}{c|c|c|c}
\hline Permeant fluid & $\begin{array}{c}\mathrm{CaCl}_{2} \text { concentration } \\
(\mathrm{mol} / \mathrm{L})\end{array}$ & $\begin{array}{c}\mathrm{Ca}^{2+} \text { concentration } \\
(\mathrm{mg} / \mathrm{L})\end{array}$ & $\begin{array}{c}\text { Electrical conductivity } \\
(\mathrm{ms} / \mathrm{m})\end{array}$ \\
\hline Tap water & -- & 15.8 & 95 \\
$\mathrm{CaCl}_{2}$ solution & 0.2 & 5120.4 & 8230 \\
\hline
\end{tabular}

The particle size distribution curves of Fujian standard sand and the four types of clay are shown in Fig. 1. It can be seen from the figure that apart from the relatively large particle size of bentonite, the particle size distribution, clay content and fine granule content of the other 3 types of clay are similar.

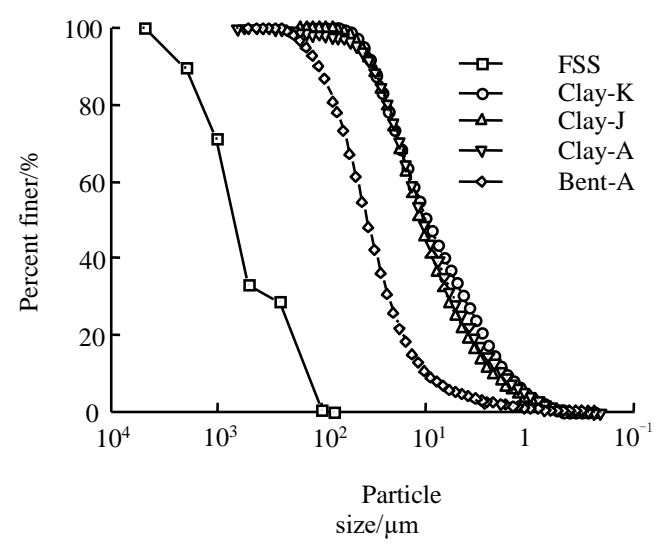

Figure 1. Particle size distributions of the five soils in this study

\section{Sample preparation}

The standard sand is mixed uniformly with a certain amount of clay, and then mixed with the prepared 5\% mud (Rumer and Ryan, 1995) to form a pouring sample similar to concrete mortar. To simulate the backfill mixture used in actual construction, the slump of the permeable sample is controlled within the range of $100 \sim 150 \mathrm{~mm}$. In the 
experiment, the additive amount of clay of $10 \%$ (percentage of the clay dry mass to the standard sand dry mass) is used.

\section{Improved flexible wall permeability test}

The RST-1 flexible wall permeameter developed by Nanjing Soil Instruments is modified due to the weak self-standing property of the samples. Referring to the improvement idea for a triaxial apparatus by Min et al., a cutting ring with many holes of $3 \mathrm{~mm}$ in diameter is added to the periphery of the sample (Min et al., 2019). In this way, the sample can be self-standing, and the confining pressure can be applied to the sidewall of the sample (see Fig. 2). Compared with the rigid wall permeameter, this setup can effectively prevent the influence of sidewall seepage. At the same time, the stress state of the cut-off wall in the actual project can be simulated in a relatively real way by applying the confining pressure of $100 \mathrm{kPa}$ and then conducting the permeability test. The osmotic pressure difference is $70 \mathrm{kPa}$, the diameter of the sample is $7 \mathrm{~cm}$, and the height is $4 \mathrm{~cm}$. The test method of flexible wall permeability refers to ASTM D5084 (ASTM, 2010). During the experiment, the sample is permeated at $25^{\circ} \mathrm{C}$ room temperature.

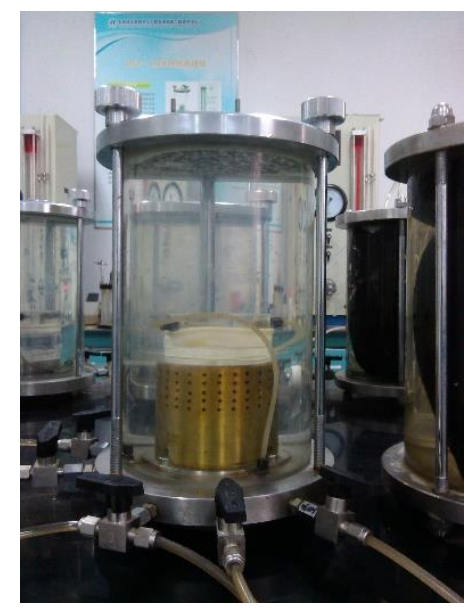

Figure 2. An improved flexible wall permeameter

\section{Bound water matric suction test}

To understand the changes of the binding state of water in the soil after adding clay, the centrifugal moisture metre is used to measure the bound water content (mass percentage of bound water and pore water) of the sample after completion of the test. The centrifugal moisture metre is based on the principle that the centrifugal force generated by high-speed rotation can separate water with low potential energy. The amounts of water retained in the sample at different speeds are measured, and then the separating potential energy is calculated according to the rotating speed. Finally, the relation between the potential energy and water is obtained. This experiment uses the Himac highspeed freezing centrifuge manufactured by HITACHI (see Fig. 3), and the detailed operation is shown in the literature (Zhu et al., 2007). 


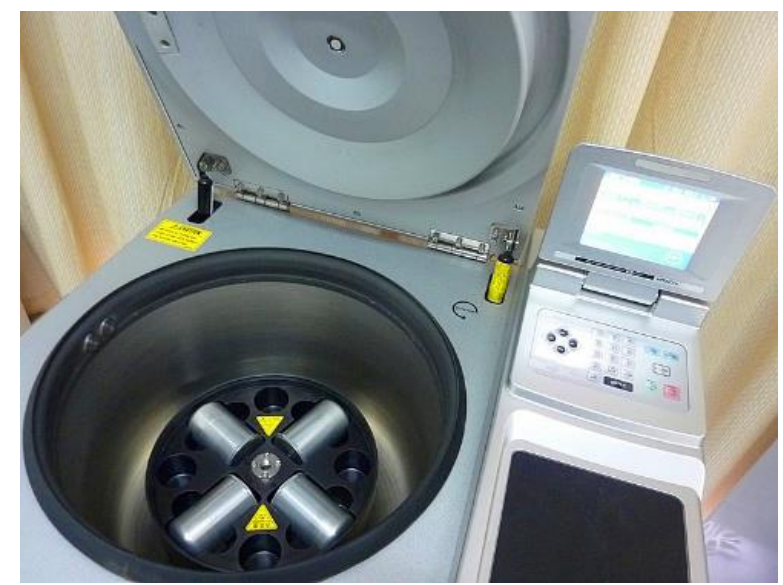

Figure 3. The centrifuge used in the test

\section{Results}

\section{Effect of $\mathrm{CaCl}_{2}$ solution on the hydraulic conductivity of the sand-clay mixture}

At the same addition rate of $10 \%$, the changes over time of the obtained hydraulic conductivity of $0.2 \mathrm{~mol} / \mathrm{L} \mathrm{CaCl}_{2}$ solution in the four sand-clay mixtures are collected, and Fig. 4 is obtained. Fig. 4(a), 4(b), 4(c), and 4(d) show the curves of hydraulic conductivity variable against time for the sand-Clay-K, sand-Clay-J, sand-Clay-A and sand-Bent-A mixtures. It can be seen from the figure that the hydraulic conductivity of sand-Clay-K, sand-Clay-A and sand-Bent-A increases to varying degrees, except for the hydraulic conductivity of the sand-Clay-J mixture, which decreases slightly, and the hydraulic conductivity of sand-Clay-K, sand-Clay-A and sand-Bent-A increases to some extent. The hydraulic conductivity of sand-Clay-K and sand-Clay-A fluctuates by one order of magnitude, but the hydraulic conductivity of sand-Bent-A mixture varies greatly. During the process, the maximum hydraulic conductivities of sand-Clay-K, sand-Clay-J, sandClay-A and sand-Bent-A are $3.517 \times 10^{-5} \mathrm{~cm} / \mathrm{s}, 3.018 \times 10^{-5} \mathrm{~cm} / \mathrm{s}, 3.278 \times 10^{-5} \mathrm{~cm} / \mathrm{s}$, $3.129 \times 10^{-5} \mathrm{~cm} / \mathrm{s}$, respectively.

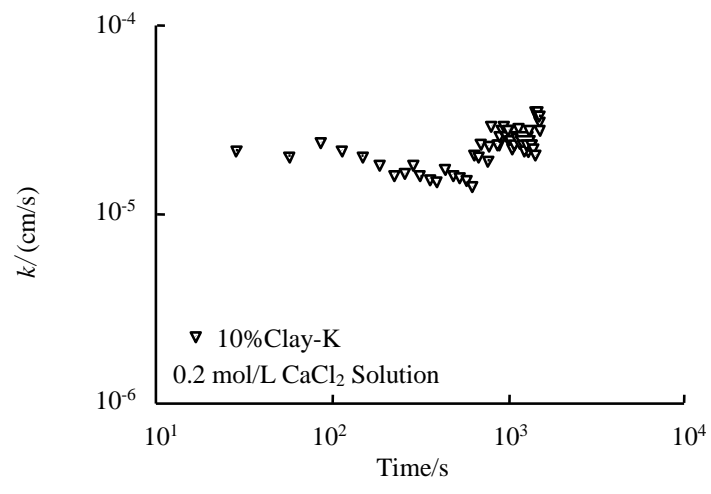

(a) adding $10 \%$ Clay-K 


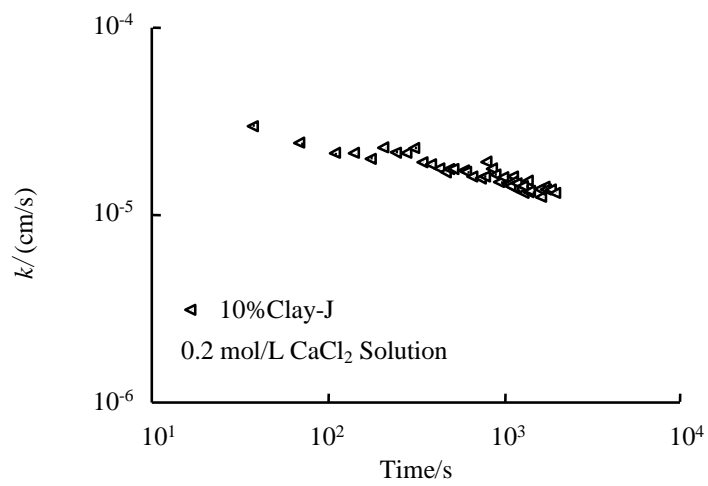

(b) adding $10 \%$ Clay-J

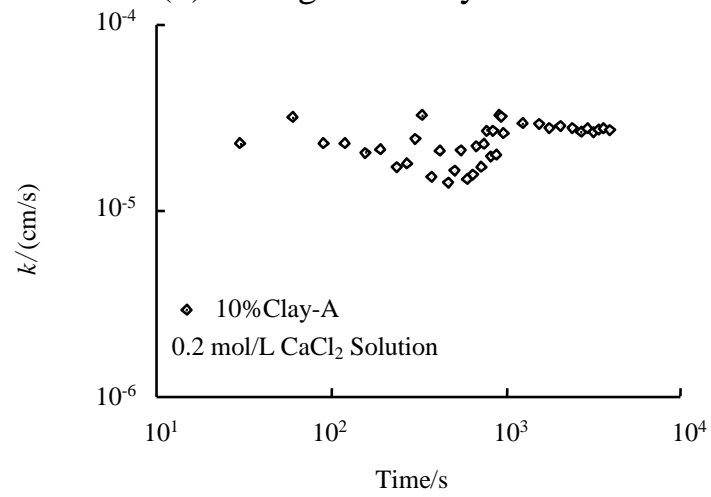

(c) adding $10 \%$ Clay-A

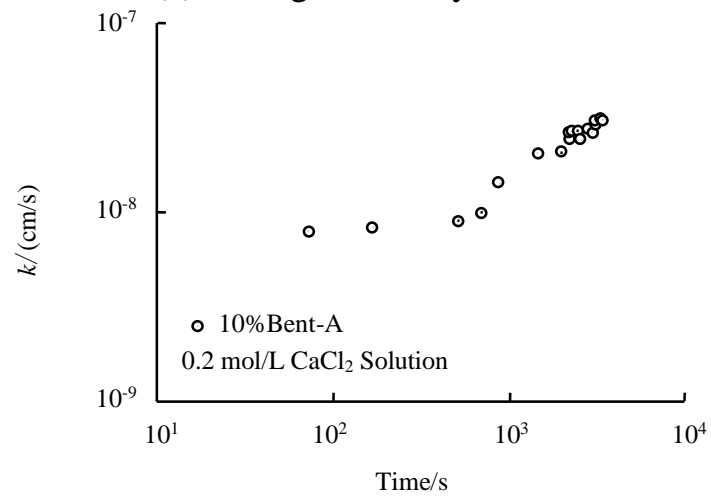

(d) adding $10 \%$ Bent-A

Figure 4. Changes of the hydraulic conductivity of the sand-clay mixtures with time

Table 4. Hydraulic conductivity $k$ with the permeant fluid of tap water or $\mathrm{CaCl}_{2}$ solution

\begin{tabular}{c|c|c|c|c}
\hline \multirow{2}{*}{ Permeant fluid } & \multicolumn{3}{|c}{$k /(\mathbf{c m} / \mathbf{s})$} \\
\cline { 2 - 5 } & sand-Clay-K & sand-Clay-J & sand-Clay-A & sand-Bent-A \\
\hline Tap water & $1.064 \times 10^{-5}$ & $3.222 \times 10^{-6}$ & $3.979 \times 10^{-6}$ & $3.169 \times 10^{-9}$ \\
$\mathrm{CaCl}_{2}$ solution & $3.238 \times 10^{-5}$ & $1.470 \times 10^{-5}$ & $2.758 \times 10^{-5}$ & $2.811 \times 10^{-8}$ \\
\hline
\end{tabular}


In addition, the stabilized hydraulic conductivities of tap water and $\mathrm{CaCl}_{2}$ solution are compared and analysed in four kinds of sand-clay mixtures with $10 \%$ content, as shown in Table 4 and Fig. 5.

In contrast, the final hydraulic conductivity ratios of $\mathrm{CaCl}_{2}$ solution and tap water in sand-Clay-K and sand-Clay-J are less than 5, but the hydraulic conductivity ratio of $\mathrm{CaCl}_{2}$ solution and tap water in sand-Clay-A and sand-Bent-A is between 5 and 10 .

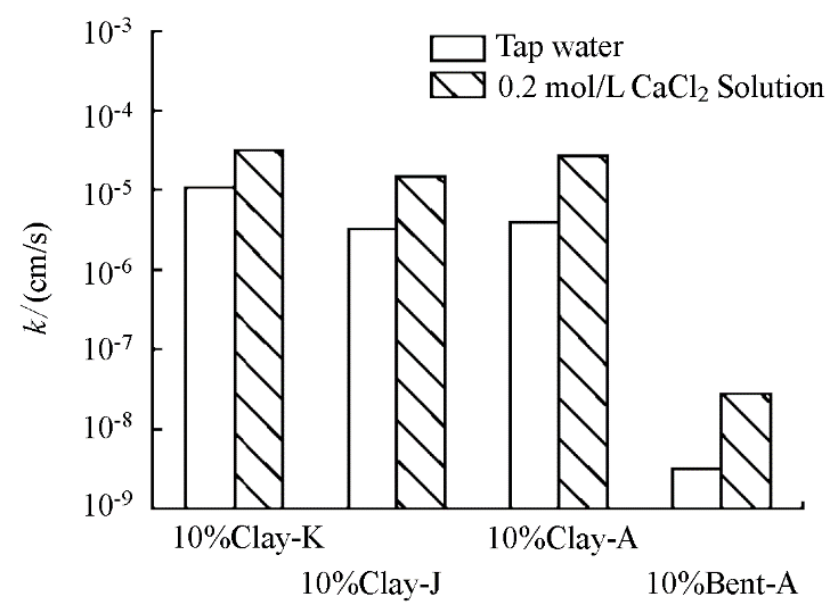

Figure 5. Hydraulic conductivity of the mixture permeated by tap water or $\mathrm{CaCl}_{2}$ solution

\section{Effect of $\mathrm{CaCl}_{2}$ solution on the porosity of the sand-clay mixture}

Previous studies have analysed the changes of hydraulic conductivity on the basis of changes in the porosity. The porosity $n$ of the samples after permeation by tap water and $\mathrm{CaCl}_{2}$ solution are also measured and calculated in the four sand-clay mixtures, respectively. The comparison of porosity between tap water and $\mathrm{CaCl}_{2}$ solution is obtained, which is shown in Fig. 6 and Table 5.

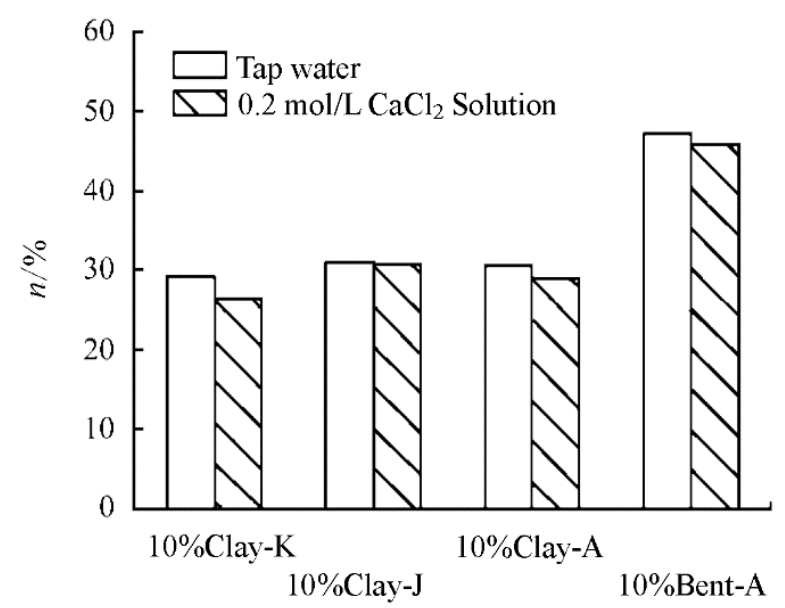

Figure 6. The porosities of sand-clay mixtures permeated by tap water or $\mathrm{CaCl}_{2}$ solution

Overall, the porosity of tap water and $\mathrm{CaCl}_{2}$ solution in the four sand-clay mixtures after permeation do not change significantly but generally decrease, because the chemical 
reaction between $\mathrm{CaCl}_{2}$ and the clay minerals forms a small number of new compounds (Yanful et al., 1995), which clog the internal water-conducting pore channels in the mixture, resulting in the reduction of porosity. Thus, for a sand-clay mixture, the hydraulic conductivity of the mixture changes over time during the whole process of permeation by $\mathrm{CaCl}_{2}$ solution.

Table 5. The porosity $n$ of the sand-clay mixtures permeated by tap water or $\mathrm{CaCl}_{2}$ solution

\begin{tabular}{c|c|c|c|c}
\hline \multirow{2}{*}{ Permeant fluid } & \multicolumn{4}{|c}{$n / \%$} \\
\cline { 2 - 5 } & sand-Clay-K & sand-Clay-J & sand-Clay-A & sand-Bent-A \\
\hline Tap water & 29.26 & 31.05 & 30.72 & 47.07 \\
$\mathrm{CaCl}_{2}$ solution & 26.24 & 30.63 & 28.82 & 45.57 \\
\hline
\end{tabular}

\section{Effect of $\mathrm{CaCl}_{2}$ solution on the bound water content of the sand-clay mixture}

The permeability of soil has a certain relationship with the pore size, and it may also have a certain relationship with the form of water in the pores. When researching the micro electric field effect of the seepage of tiny-particle clay, Liang et al. found that the bonding of soil particle surfaces will affect the permeability of the soil under the interaction of a clay-water-electrolyte system (Liang et al., 2010). Based on the consideration of whether the bound water has an effect on the permeability of the mixture, moisture centrifugal dehydration is carried out on the mixtures to determine the $p F$ value of the binding potential energy of the pore water in each sample (logarithm of the centimetre height of the water column of the water suction in the soil), which is shown in Fig. 7. Referring to the research result of Lebedev, the $p F$ value of 3.8 is used to distinguish bound water from free water (Lebedev, 1936). The bound water content in mixture can be obtained from the intercept of the moisture content with the $p F$ value of more than 3.8 from the water characteristic curve. Fig. 8 and Table 6 show the comparison of the content of bound water between the effects of tap water and $\mathrm{CaCl}_{2}$ solution after permeation in the four kinds of sand-clay mixtures.

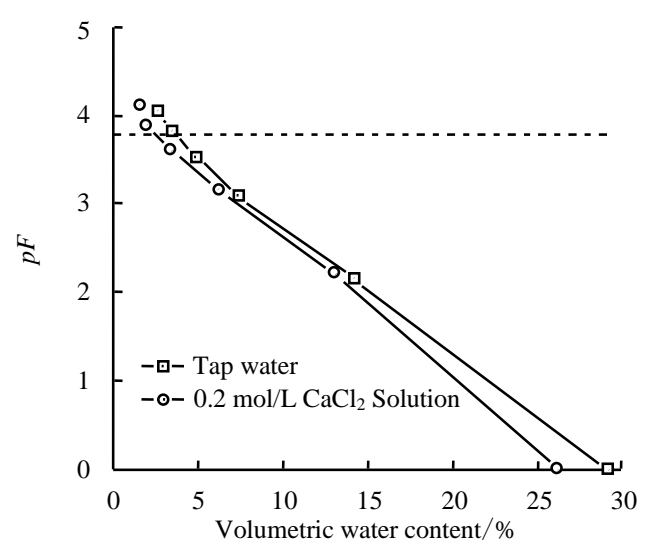

(a) adding $10 \%$ Clay-K

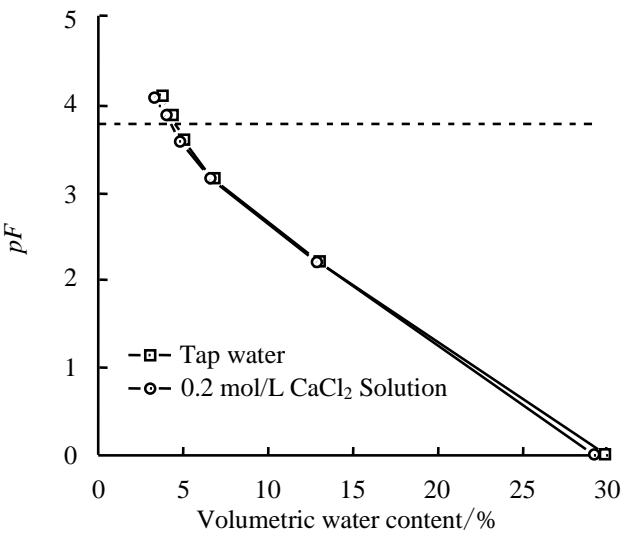

(b) adding $10 \%$ Clay-J 


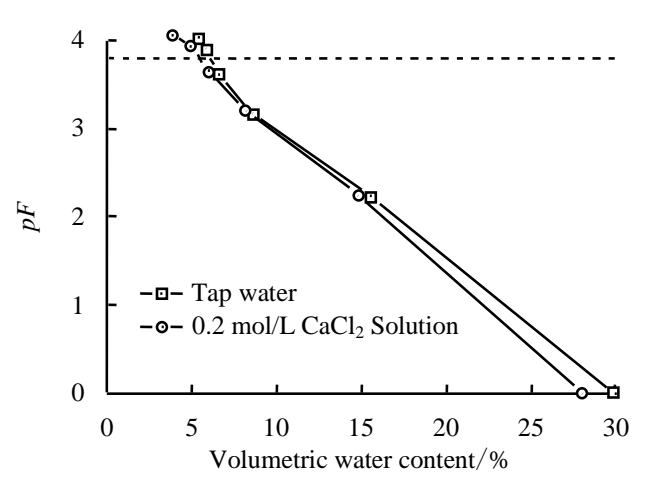

(c) adding $10 \%$ Clay-A

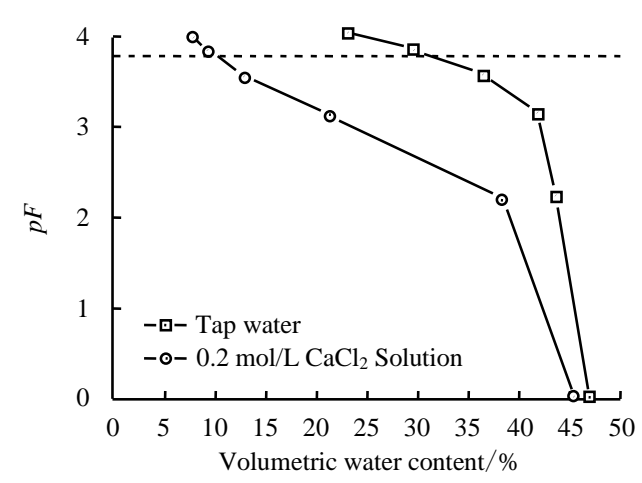

(d) adding $10 \%$ Bent-A

Figure 7. Soil-water characteristic curves of mixtures permeated by tap water or $\mathrm{CaCl}_{2}$ solution

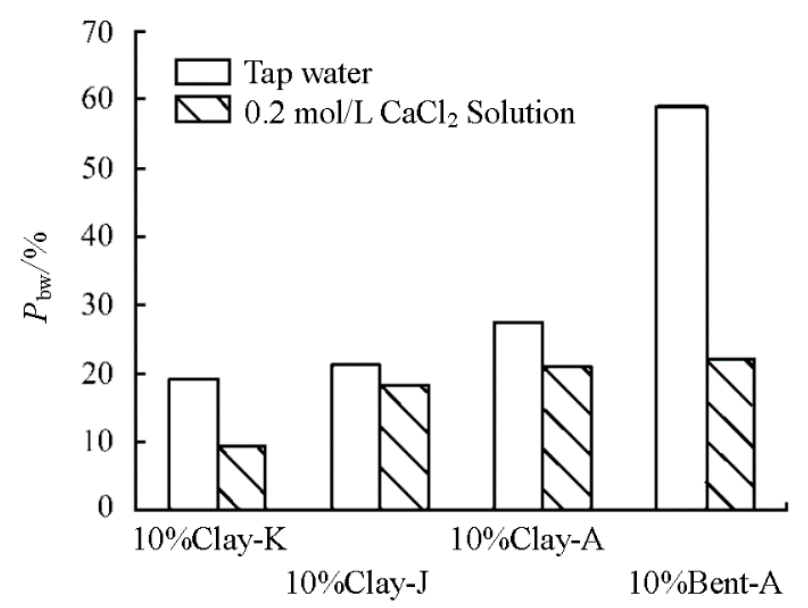

Figure 8. Bound water percentages $P_{\mathrm{bw}}$ of sand-clay permeated by tap water or $\mathrm{CaCl}_{2}$ solution

Table 6. Bound water percentages with the permeant liquid of tap water or $\mathrm{CaCl}_{2}$ solution

\begin{tabular}{c|c|c|c|c}
\hline \multirow{2}{*}{ Permeant fluid } & \multicolumn{4}{|c}{ Bound water percentage $\boldsymbol{P}_{\mathbf{b w}} / \%$} \\
\cline { 2 - 5 } & sand-Clay-K & sand-Clay-J & sand-Clay-A & sand-Bent-A \\
\hline Tap water & 19.15 & 21.16 & 27.41 & 59.03 \\
$\mathrm{CaCl}_{2}$ solution & 9.31 & 18.18 & 20.91 & 22.15 \\
\hline
\end{tabular}

Compared with those using tap water, the bound water content of the samples using $\mathrm{CaCl}_{2}$ solution in sand-Clay-K, sand-Clay-J, sand-Clay-A and sand-Bent-A mixtures after permeation decrease to some extent. In addition, the change of the bound water content of the sand-Bent-A mixture is the largest. 


\section{Discussion}

By combining Fig. 5 and Fig. 6 , it can be seen that the hydraulic conductivity of $\mathrm{CaCl}_{2}$ solution in the four kinds of sand-clay mixture after permeation increases to varying degrees and that the corresponding porosity does not increase but decreases slightly. This is different from the common phenomenon in which the porosity of clay minerals decreases and the hydraulic conductivity decreases (Mesri and Olson, 1971). Thus, It is speculated that in the process of permeation of the sand-clay mixture, the water with a certain degree of binding ability to clay particles in the pore water is relatively stagnant. It may be an abnormal liquid with mechanical properties between those of a solid and a liquid (Sridharan et al., 1986) and showing viscosity, that is, there is a water film with a large binding potential energy to soil particles around the clay particles. This is the inner layer-Stern layer of the diffused double layer (stern layer) (Yuan, 2012), as shown in Fig. 9.

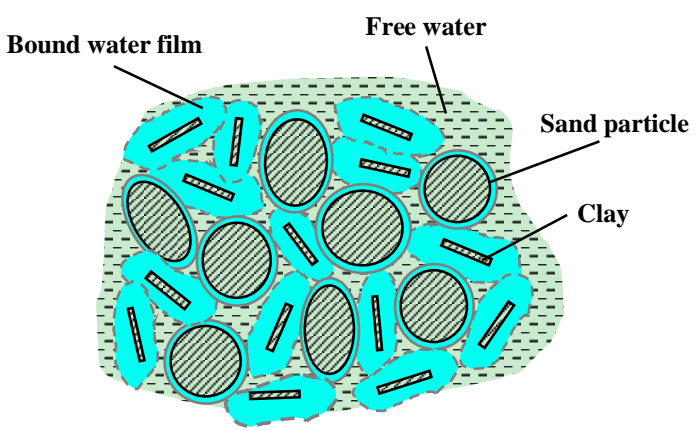

Figure 9. Schematic diagram of a sand-clay mixture sample

Based on the above assumptions, the calculation method (Equation 1) of the effective porosity $n_{\text {eff }}$ is proposed:

$$
n_{\mathrm{eff}}=n\left(1-P_{\mathrm{bw}}\right)
$$

where $P_{\mathrm{bw}}$ is the bound water content in the pore water of the sand-clay mixture.

The effective porosities of the four kinds of sand-clay mixtures are calculated after permeation by tap water and $\mathrm{CaCl}_{2}$ solution, respectively, as shown in Fig. 10 .

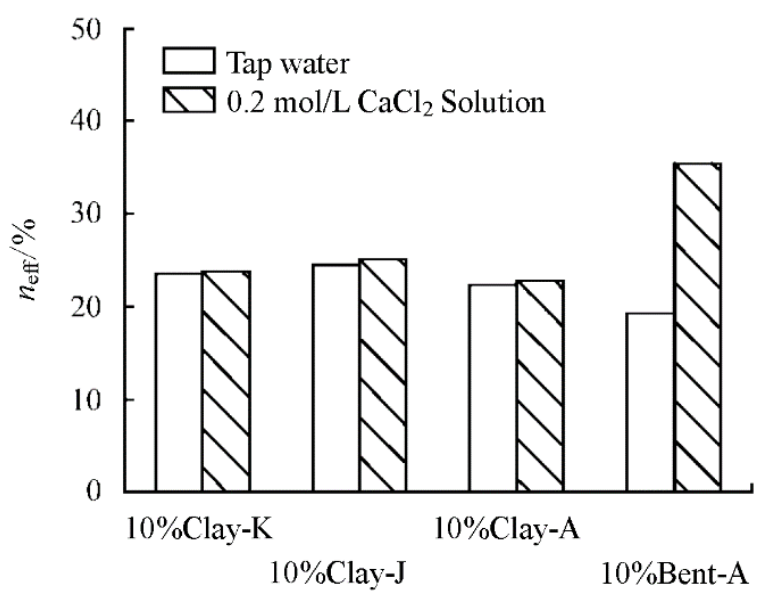

Figure 10. Effective porosity neff of sand-clay permeated by tap water or $\mathrm{CaCl}_{2}$ solution 
It can be seen directly from Fig. 10 that for the four kinds of sand-clay mixtures, the final hydraulic conductivity after permeation with $\mathrm{CaCl}_{2}$ solution is increased to varying degrees. This is because although the porosity of the mixture does not change much, or even decreases, the effective porosities of the four kinds of sand-clay mixtures increase, which may be the main reason for the increase of the final hydraulic conductivities of the mixtures. In my opinion, there is a replacement reaction between the calcium ions in the permeant fluid and the univalent metal cations (such as sodium and potassium ions) adsorbed onto the surface of the clay mineral particles. The thickness of the diffused double layer on the surface of the clay mineral particles becomes thinner, and the corresponding bound water content decreases (Gu and Fang, 2009), which results in the increase of the effective porosity and the increase of the hydraulic conductivity of the mixture.

\section{Conclusions}

Based on discussions of the test results and further analysis, the following conclusions can be made:

(1) The self-modified flexible wall permeameter is used, and permeability tests of tap water and $0.2 \mathrm{~mol} / \mathrm{L} \mathrm{CaCl}_{2}$ solution in sand-Clay-K, sand-Clay-J, sand-Clay-A and sandBent-A mixtures are conducted. The results show that when the additive amount of clay is $10 \%$ and the confining pressure is $100 \mathrm{kPa}$, compared with the effects of tap water, the hydraulic conductivity of the sand-clay mixture increases in varying degrees when $\mathrm{CaCl}_{2}$ solution is used as the permeant fluid. However, with an increase of the hydraulic conductivity by 10 times, the porosity of $\mathrm{CaCl}_{2}$ solution in the four mixtures decreases slightly after permeation. It is proven that the seepage-control function of the sand-BentA mixture used as the material for landfill cut-off walls at the addition rate of $10 \%$ can meet the requirement.

(2) The experimental results show that the calcium ion in the permeant fluid is replaced by the univalent cation on the surface of clay mineral particles, which results in the decrease of the thickness of the diffused double layer and the decrease of the bound water content, leading to the increase of the effective porosity. Macroscopically, the hydraulic conductivity of the mixture becomes larger.

(3) In this study, the permeability tests were conducted under calcium chloride solution. However, in fact the contaminants in the landfill leachate may also include inorganic matters and organic matters. Thus, the chemical compatibility of cut-off walls in the presence of composite contaminations, the interaction between clay particle and contaminated fluid is recommended. On-going additional research is aimed at addressing all of the limitations.

Acknowledgements. The authors would like to acknowledge the Open Fund of Joint Technology Transfer Center of Yancheng Polytechnic College (Grant No. YGKF-201810), Key Research and Development Program (Social Development) Project of Zhenjiang (Grant No. SH2018024), National Natural Science Foundation of China (Grant No. 51579119) for supporting this study. 


\section{REFERENCES}

[1] ASTM Committee D5084. (2010): Standard test methods for measurement of hydraulic conductivity of saturated porous materials using a flexible wall permeameter. - ASTM International.

[2] Devlin, J. F., Parker, B. L. (1996): Optimum hydraulic conductivity to limit contaminant flux through cutoff walls. - Groundwater 34(4): 719-726.

[3] Fan, R. D., Du, Y. J., Liu, S. Y., Chen, Z. B. (2013): Engineering behavior and sedimentation behavior of lead contaminated soil-bentonite vertical cutoff wall backfills. Journal of Central South University 20(8): 2255-2262.

[4] Fei, P. Y., Ji, R., Zhang, D. L. (2005): Laboratory research on the properties of containment wall material of Shanghai Laogang municipal sanitary waste landfill. - Shanghai Geology (4): 51-53.

[5] Grube, W. E. (1992): Slurry trench cut-off walls for environmental pollution control. - In Slurry Walls: Design, Construction, and Quality Control. ASTM International.

[6] Gu, R. G., Fang, Y. G. (2009): Experimental research on ion effects of ultrafine granular clay seepage. - Rock and Soil Mechanics 30(6): 1595-1598.

[7] Hu, P., Yang, Q. (2012): Experimental study of swelling characteristics of bentonite-sand mixture. - Rock and Soil Mechanics 33(2): 453-458.

[8] Jing, X. D., Ruan, W. J., Dai, G. Z. (2006): Present state of antiseepage techniques used in waste landfill sites. - Journal of Changchun Institute of Technology (Natural Sciences Edition) 7(1): 1-4.

[9] Jo, H. Y., Benson, C. H., Shackelford, C. D., Lee, J. M., Edil, T. B. (2005): Long-term hydraulic conductivity of a geosynthetic clay liner permeated with inorganic salt solutions. - Journal of Geotechnical and Geoenvironmental Engineering 131(4): 405-417.

[10] Jo, H. Y., Katsumi, T., Benson, C. H., Edil, T. B. (2001): Hydraulic conductivity and swelling of nonprehydrated GCLs permeated with single-species salt solutions. - Journal of Geotechnical and Geoenvironmental Engineering 127(7): 557-567.

[11] Katsumi, T., Ishimori, H., Onikata, M., Fukagawa, R. (2008): Long-term barrier performance of modified bentonite materials against sodium and calcium permeant solutions. - Geotextiles and Geomembranes 26(1): 14-30.

[12] Kolstad, D. C., Benson, C. H., Edil, T. B. (2004): Hydraulic conductivity and swell of nonprehydrated geosynthetic clay liners permeated with multispecies inorganic solutions. - Journal of Geotechnical and Geoenvironmental Engineering 130(12): 1236-1249.

[13] Lebedev, A. F. (1936): Soil and groundwaters. - The Academy of Sciences of the USSR, Moscow, Russia.

[14] Lee, J. M., Shackelford, C. D., Benson, C. H., Jo, H. Y., Edil, T. B. (2005): Correlating index properties and hydraulic conductivity of geosynthetic clay liners. - Journal of Geotechnical and Geoenvironmental Engineering 131(11): 1319-1329.

[15] Liang, J. W., Fang, Y. G., Gu, R. G. (2010): Analysis of microelectric field effect of seepage in tiny-particle clay. - Rock and Soil Mechanics 31(10): 3043-3050.

[16] Mesri, G., Olson, R. E. (1971): Mechanisms controlling the permeability of clays. - Clays and Clay Minerals 19(3): 151-158.

[17] Patton, P., Day, S., Byle, M. (2007): Compatibility evaluation of groundwater cutoff wall using salt-resistant bentonite and BFS/cement for deep-mix barrier wall. - In Soil Improvement (pp. 1-11).

[18] Rumer, R. R., Ryan, M. E. (1995): Barrier containment technologies for environmental remediation applications. - Wiley-Interscience, New York.

[19] Shackelford, C. D., Benson, C. H., Katsumi, T., Edil, T. B., Lin, L. (2000): Evaluating the hydraulic conductivity of GCLs permeated with non-standard liquids. - Geotextiles and Geomembranes 18(2-4): 133-161.

[20] Sridharan, A., Rao, S. M., Murthy, N. S. (1986): Compressibility behavior of homogenized bentonite. - Geotechnique 36(4): 551-564. 
[21] Yanful, E. K., Shikatani, K. S., Quirt, D. H. (1995): Hydraulic conductivity of natural soils permeated with acid mine drainage. - Canadian Geotechnical Journal 32(4): 624-646.

[22] Yao, Y. C., Bao, Z. W. (2008): Application of vertical cut-off curtain to sanitary landfill site in plain areas. - Environmental Engineering 26(3): 29-32.

[23] Yuan, J. B. (2012): The study of properties of bound water in clayey soils and their quantitative methods. - South China University of Technology, Guangzhou, China.

[24] Min, F., Du, J., Zhang, N., Chen, X., Lv, H., Liu, L., Yu, C. (2019): Experimental study on property change of slurry and filter cake of slurry shield under seawater intrusion. Tunnelling and Underground Space Technology 88: 290-299.

[25] Zhu, W., Zhang, C. L., Chiu, A. C. (2007): Soil-water transfer mechanism for solidified dredged materials. - Journal of Geotechnical and Geoenvironmental Engineering 133(5): 588-598. 